\title{
A comparative study of metformin alone, in combination with insulin or metformin plus insulin in presence of simvastatin in libyan diabetic patients
}

\begin{abstract}
Type 2 of diabetes mellitus (DM) is associated with progressive failure of pancreatic B-cells to secrete insulin, decreased insulin action, due to reduced insulin receptors at the target sites. Dyslipidemia is a common risk of DM and is responsible to a large extent for cardiovascular disease-related morbidity and mortality. This study was planned to compare the effects of metformin alone and a combination of metformin and insulin in presence of simvastatin on glycemic and lipid levels in Libyan diabetic patients. This retrospective study was conducted at Benghazi Diabetic Center (Libya) on 100 patients with type 2 DM of 40-60years old. Patients were selected for follow up on basis of inclusion and exclusion criteria, and were divided into three groups. The first group $(\mathrm{n}=30)$, received metformin $(1-2 \mathrm{gm} /$ day $)$. The second group $(\mathrm{n}=40)$ received metformin (1-2gm/day) and insulin (mixtard 30/70, 30-60units/day) and third group $(\mathrm{n}=30)$ received metformin $(1-2 \mathrm{gm} /$ day), insulin (30-60units/day) plus simvastatin (40mg/day). Glucose blood levels (FBG, PPBG and HBA1c), lipid profile (TC, TG, HDL-C, LDL-C and AI), hepatic function (ALT, AST, ALP and Bilirubin) and renal function (creatinine and urea) were measured for each patient. All the patients had a good glycemic control with significant decrease in $\mathrm{HbAcl}$ of metformin plus insulin treated group. No significant differences in lipid profile of metformin treated group and metformin plus insulin treated group were observed. Date revealed both significant increase in HDL-C and decrease in TC, LDL-C and atherogenic index levels but without any change in TG in metformin and insulin treated group as compared with metformin, insulin plus simvastatin treated group. All the findings of hepatic and renal functions were within the normal range except for bilirubin which significantly increased in metformin, insulin plus simvastatin treated group compared with other treated groups. In conclusion, the efficacy of metformin in controlling hyperglycemia was enhanced with insulin without negative effects. Simvastatin was effective in controlling dyslipidemia associated with DM and produced a profound reduction in TC and LDL-C of the patients.
\end{abstract}

Keywords: selective transfer, superficial layer, structural analysis, intensity x-rays, width of diffraction lines, crystalline network constant
Volume 5 Issue 2 - 2017

Fadya A Menesi,' Fathi M Sherif, ${ }^{2}$ Maha ElGharadwi, ${ }^{3}$ Esamm El-Denna, ${ }^{4}$ Saleh Mursi, ${ }^{5}$ Ghazala Othman, ${ }^{3}$ Mustfa Y Younis, ${ }^{6}$ Faraj El-Shari, ${ }^{6}$ Abdelkader H. El-Debani, ${ }^{3}$ Awad G Abdellatif ${ }^{3}$

'Department of Internal Medicine, Nephrology Unit, Faculty of Medicine, University of Tobruk, Libya

${ }^{2}$ Department of Pharmacology, Faculty of Pharmacy, University of Tripoli, Libya

${ }^{3}$ Department of Pharmacology, Faculty of Medicine, University of Benghazi, Libya

${ }^{4}$ Department of Nutrition, Faculty of Public Health, University of Benghazi, Libya

${ }^{5}$ Department of Community Medicine, University of Benghazi, Libya

${ }^{6}$ Department of Biochemistry, Faculty of Medicine, University of Benghazi, Libya

Correspondence: Fathi Mohamed Sherif, Department of Pharmacology and Clinical Pharmacy, University of Tripoli, Tripoli, Libya,Tel 0021891 21। 7258,Email Fmosherif@yahoo.com

Received: February 08, 2017 | Published: March 31, 2017
Abbreviations: DM, diabetes mellitus; CVD, cardiovascular disease; TC, total cholesterol; TG, triglyceride; HDL-C, high density lipoprotein; LDL-C, low density lipoprotein; AI, anthrogenic index; FBG, fasting blood glucose; PPBG, postprandial blood glucose; HbAlc, glycated hemoglobin; ALT, alanine aminotransferase; AST, asparate aminotransferase; ALP, alkaline phosphatase; DM, diabetes mellitus

\section{Introduction}

Diabetes Mellitus (DM) is one of the four major noncommunicable diseases along with cardiovascular disease (CVD), cancer and chronic respiratory diseases. Once a disease of affluence, it is now increasingly common among the poor countries. ${ }^{1}$ Worldwide, in 2010, an estimated of 285 million people had type 2 DM. Type 2 accounts for $90 \%$ of all the cases of DM. ${ }^{2}$ The greatest number of people with DM is between 40 and 59years of age. ${ }^{3}$ World Health Organization (WHO) defines DM as a metabolic disorder of multiple etiologies characterized by chronic hyperglycemia with disturbances of carbohydrate, fat and protein metabolism. DM type 2 results from defects in insulin secretion, insulin action or both and insulin resistance. The significant morbidity and mortality associated with DM arises from minor and macrovascular complications, ischemic heart disease and peripheral vascular disease. ${ }^{4}$ Metformin is an oral anti-diabetic drug which belongs to biguanide class. Metformin is usually the first line drug for treatment of type 2 DM. In general, it is prescribed for newly diagnosed patients in conjunction with exercise and weight loss, as opposed to in the past, where it was prescribed after diet and exercise had failed. Metformin acts by several mechanisms of action but the major mechanism is inhibiting hepatic gluconeogenesis. ${ }^{5}$ The average person with type 2 DM has three times the normal rate of gluconeogenesis, metformin treatment reduces by one third. ${ }^{6}$ Metformin stimulates AMP1 activated protein kinase, AMPK, an enzyme that plays a key role in insulin signaling, whole energy balance and the metabolism of glucose and fats.? Activation of AMPK is required for metformin's inhibiting effect on hepatic gluconeogenesis. ${ }^{8}$ Metformin may antagonize the action of glucagon, thus reducing fasting blood glucose (FBG). ${ }^{9}$ In addition, metformin increases insulin action at target sites, enhances peripheral glucose uptake, increases fatty acid oxidation and reduces absorption of glucose from gastrointestinal tract. The increased peripheral 
utilization of glucose may be due to improved insulin receptors. ${ }^{10}$ Diabetes mellitus and statins have a complex association and are the attention of patient and healthcare debate. Statins are widely used as a part of DM care due to that patients with DM have a greater CVD. ${ }^{11}$ Simvastatin belongs to the statins class. It is an oral antihyperlipidemic drug that reduces the risk of atherosclerosis and its complications. It controls dyslipidemia associated with type 2 $\mathrm{DM}^{12,13}$ and acts by competitively inhibiting HMG-CoA reductase, the major rate limiting enzyme of HMG-CoA reductase pathway. Because simvastatin is similar to HMG-CoA on a molecular level, it takes the place of HMG-CoA in enzyme and inhibits HMGCoA reductase, so blocks cholesterol (TC) synthesis in the liver. TC synthesis opposes to occur mostly at night, ${ }^{14}$ so simvastatin with a short half-life, is usually taken at night to maximize its effect. It also increases LDL uptake in the liver. One of the possible mechanism of hyperglycemia associated with simvastatin is by inhibition of HMG-CoA reductase..$^{15,16}$ Thus, this study was aimed to explore the efficacy and safety of metformin in combination with insulin and in presence of simvastatin in diabetic Libyan patients

\section{Materials and methods}

Hundred Libyan patients with type $2 \mathrm{DM}$ were selected for this retrospective study. This study was conducted at Benghazi Diabetic Center (BDC), Benghazi, Libya during 2016. This study was approved by local ethical committees of both BDC and University of Benghazi (UoB). The patients were aged between 40-60years and had HbA1c $\geq 7 \%$ as well as received treatment for more than twoyears. The exclusion criteria were: pregnancy, breast feeding, acute myocardial infraction (MI), congestive heart failure (CHF), renal and hepatic diseases, ketoacidosis, patient on lipid lowering drugs except for the third group (see below). Patients who did not respond to the treatment or who were subjected to change in treatment regimen during the period of the study were excluded.

\section{Patients were divided into three groups:}

Group I: Type 2 DM patients $(\mathrm{n}=30)$ on metformin alone as a monotherapy in a dose of $1-2 \mathrm{gm} /$ day.

Group II: Type 2 DM patients (n=40) on metformin (1-2gm/day) and human insulin (mixtard 30/70): mixture of short acting (30\%) and long acting insulin (70\%) in a dose of 30-60units/day.

Group III: Type 2 DM patients $(\mathrm{n}=30)$ on metformin and insulin as in group II plus simvastatin in a dose of $40 \mathrm{mg} /$ day.

\section{Glucose levels}

Fasting blood glucose (FBG), postprandial blood glucose (PPBG) and glycated hemoglobin $(\mathrm{HbAlc})$, lipid profile: total cholesterol (TC), triglyceride (TG), high density lipoprotein (HDL-C), low density lipoprotein (LDL-C), hepatic function parameters (ALT, AST, ALP and bilirubin) and renal function parameters (creatinine and urea) were all measured for each patient of each group. All parameters were estimated after an overnight fast except that PPBG which was estimated 24hours after lunch. Atherogenic index (AI) was calculated according to Rahman et al., ${ }^{17}$ using the following expression formula: $\mathrm{A}=\mathrm{TC}(\mathrm{mg} / \mathrm{dl}) / \mathrm{HDL}-\mathrm{C}(\mathrm{mg} / \mathrm{dl})$. All biochemical investigations were carried out at the Clinical Biochemistry Lab. of Benghazi Diabetic Center (BDC), Benghazi, Libya.

\section{Statistical analysis}

Data was expressed as mean \pm SD. Statistical analysis was tested by analysis of ariance (one way ANOVA) for overall differences. Comparisons between individual groups were tested by post-hoc test (LSD). $\mathrm{P}$ value of $<0.05$ was taken as significant.

\section{Results}

In Table 1, analysis of data by one-way ANOVA followed by posthoc test revealed no significant change in the levels of FBG of all the patients $(\mathrm{p}=0.432)$. While the level of PPBG showed a significant decrease $(p<0.05)$ in patients treated by metformin and insulin as compared to patients treated with metformin alone. The analysis of data also revealed that there is no significant change in PBG $(p=0.440)$ in patients treated by insulin and metformin as compared to metformin, insulin and simvastatin group. In Table 1 also, there is a very highly significant decreased in the level of HbAlc in metformin and insulin treated group as compared to metformin alone treated group $(\mathrm{p}<0.001)$. The analysis, on the other hand, revealed no significant change in the level of HbAlc of metformin and insulin treated patients compared to metformin, insulin and simvastatin treated patients $(\mathrm{p}=0.351)$.

Table 2 shows the effects of the three regimens on lipid profile of Libyan diabetic patients. Thus, an analysis of data of the total TC levels in metformin alone and in metformin with insulin treated patients indicated no significant change $(\mathrm{p}=0.259)$. However, there was a very highly significant reduction in the TC level of the metformin, insulin and simvastatin treated group as compared to metformin and insulin treated patients $(\mathrm{p}<0.001)$.

In Table 2, no significant change $(\mathrm{p}=0.140)$ was found in the level of TG of all the three groups with regard to TG. As shown also in table 2, the analysis of the levels of HDL-C indicated a nonsignificant increase in patients treated by metformin and insulin compared to metformin alone $(\mathrm{p}=0.079)$. On the other hand, an analysis of the data revealed a significant increase in HDL-C levels in metformin, insulin and simvastatin treated patients as compared to the patients treated with metformin and insulin $(\mathrm{p}<0.05)$.

With regard to LDL-C, there is no significant change $(\mathrm{p}=0.794)$ in LDL-C levels of metformin and insulin treated group as compared to metformin alone $(p=0.794)$. While the level of LDL-C was very highly significantly decreased in metformin, insulin and simvastatin patients as compared with metformin and insulin treated group $(\mathrm{p}<0.001$, Table 2). Also, in Table 2, upon analysis of data of AI, no significant change in AI values of metformin and insulin treated group as compared to metformin alone $(\mathrm{p}=0.445)$ was observed. However, very highly significantly decreased in AI in patients treated by metformin, insulin and simvastatin when compared to the patients treated with metformin and insulin $(\mathrm{p}<0.001)$.

Data presented in Table 3 indicates that there is no significant change in enyzmes activities of ALT, AST and ALP in metformin and insulin treated patients as compared to metformin alone $(\mathrm{p}=0.364$, $\mathrm{p}=0.112$ and $\mathrm{p}=0.441$, respectively). In addition, no significant change in their levels in metformin, insulin and simvastatin treated group as compared to the metformin and insulin treated group. With regard to bilirubin, an analysis of the data indicated that the level of bilirubin was highly significantly increased in metformin, insulin and simvastatin treated group as compared to the other two groups $(\mathrm{p}<0.01)$.

In Table 4, a statistical analysis of the three treated groups by one-way ANOVA revealed no significant changes among the groups in both parameters of the renal function (urea and creatinine levels, $\mathrm{p}=0.946$ and $\mathrm{p}=0.124$, respectively). 
Table I Effects of metformin alone and in combination with insulin and simvastatin on glucose levels of Libyan patients with type 2 diabetes mellitus

\begin{tabular}{|c|c|c|c|}
\hline Treated group & FBG (Mg/DI) & PPBG (Mg/DI) & HbAic (\%) \\
\hline $\begin{array}{l}\text { Metformin } \\
(1-2 \mathrm{gm} / \text { day, } \mathrm{n}=30)\end{array}$ & $122.8 \pm 19.9$ & $140.8 \pm 16.2$ & $7.4 \pm 0.43$ \\
\hline $\begin{array}{l}\text { Metformin And Insulin } \\
(1-2 \mathrm{gm} / \text { day \& 30-60units/day, n=40) }\end{array}$ & $117.8 \pm 16.3$ & $133.2 \pm 10.7^{*}$ & $7.0 \pm 0.37^{* *}$ \\
\hline $\begin{array}{l}\text { Metformin, Insulin And Simvastatin } \\
(1-2 \mathrm{gm}, 30-60 \text { units \& } 40 \mathrm{mg} / \text { day, } \mathrm{n}=30)\end{array}$ & I I $6.0 \pm 24.8$ & $129.5 \pm 30.7$ & $7 . \mid 8 \pm 0.81$ \\
\hline
\end{tabular}

Data are expressed as mean \pm SD

*Significantly decreased as compared to metformin treated patients $(p<0.05)$ and

**Highly significant decreased as compared to metformin treated patients $(\mathrm{p}<0.0 \mathrm{I})$

Table 2 Effects of metformin as alone and in combination with insulin and simvastatin on lipid profile of type 2 diabetic Libyan patients

\begin{tabular}{|c|c|c|c|c|c|}
\hline Treated group & TC (mg/dl) & TG (mg/dl) & $\begin{array}{l}\text { HDL-C (mg/ } \\
\text { dl) }\end{array}$ & LDL-C (mg/dl) & $A I=T C / H D L-C$ \\
\hline $\begin{array}{l}\text { Metformin } \\
(1-2 g m / \text { day, } n=30)\end{array}$ & $162.2 \pm 16.7$ & $102.6 \pm 24.8$ & $37.0 \pm 3.2$ & $108.1 \pm 16.2$ & $4.38 \pm 0.64$ \\
\hline $\begin{array}{l}\text { Metformin and insulin } \\
(1-2 \mathrm{gm} / \text { day \& 30-60units/day, } n=40)\end{array}$ & $156.8 \pm 19.5$ & $95.9 \pm 34.6$ & $39.3 \pm 5.0$ & $107.0 \pm \mid 4.4$ & $4.22 \pm 0.75$ \\
\hline $\begin{array}{l}\text { Metformin, insulin and simvastatin } \\
(\mathrm{I}-2 \mathrm{gm}, 30-60 \text { units \& } 40 \mathrm{mg} / \text { day, } \mathrm{n}=30)\end{array}$ & $128.5 \pm 34.0 * * *$ & $80.0 \pm 54.5$ & $41.2 \pm 15 . I^{*}$ & $60.4 \pm 10.8^{* * *}$ & $3.29 \pm 1.45^{* * *}$ \\
\hline
\end{tabular}

Data are expressed as mean \pm SD

*Significantly increased as compared to the metformin and insulin treated patients $(p<0.05)$ and

*** Very highly significant decreased as compared to metformin and insulin treated patients $(\mathrm{p}<0.00 \mathrm{I})$

Table 3 Effects of metformin alone and in combination with insulin and simvastatin on liver function of type 2 diabetic Libyan patients

\begin{tabular}{|c|c|c|c|c|}
\hline Treated group & ALT (u/l) & AST (u/l) & ALP (u/l) & Bilirubin (mg/dl) \\
\hline $\begin{array}{l}\text { Metformin } \\
(\mathrm{I}-2 \mathrm{gm} / \text { day, } \mathrm{n}=30)\end{array}$ & $24.5 \pm 3.7$ & $23.5 \pm 2.7$ & $116.5 \pm 8.6$ & $0.3 I \pm 0.05$ \\
\hline $\begin{array}{l}\text { Metformin and insulin } \\
(I-2 \mathrm{gm} / \text { day \& 30-60units/day, } n=40)\end{array}$ & $25.6 \pm 3.1$ & $24.5 \pm 2.5$ & $1 \mid 3.8 \pm 8.1$ & $0.33 \pm 0.06$ \\
\hline $\begin{array}{l}\text { Metformin, insulin and simvastatin } \\
(1-2 \mathrm{gm}, 30-60 \text { units \& } 40 \mathrm{mg} / \text { day, } \mathrm{n}=30)\end{array}$ & $24.2 \pm 5.4$ & $25.5 \pm 4.8$ & $115.4 \pm 10 . .8$ & $0.37 \pm 0.05^{* *}$ \\
\hline
\end{tabular}

Data are expressed as mean \pm SD

**Highly significantly increased as compared to the other treated groups $(p<0.00 \mathrm{I})$

Table 4 Effects of metformin alone and in combination with insulin and simvastatin on renal function of type 2 diabetic Libyan patients

\begin{tabular}{|c|c|c|}
\hline Treated group & Urea (mg/dl) & Creatinine (mg/dl) \\
\hline $\begin{array}{l}\text { Metformin } \\
(1-2 g m / \text { day, } n=30)\end{array}$ & $|8.8 \pm 2|$. & $0.65 \pm 0.10$ \\
\hline $\begin{array}{l}\text { Metformin and insulin } \\
(1-2 g m / \text { day \& 30-60units/day, } n=40)\end{array}$ & $19.0 \pm 2.0$ & $0.7 I \pm 0.12$ \\
\hline $\begin{array}{l}\text { Metformin, insulin and simvastatin } \\
(\mathrm{I}-2 \mathrm{gm}, 30-60 \text { units \& } 40 \mathrm{mg} / \text { day, } \mathrm{n}=30)\end{array}$ & $19.0 \pm 3.5$ & $0.69 \pm 0.16$ \\
\hline
\end{tabular}

Data are expressed as mean \pm SD

No significant difference among the groups by one-way ANOVA

Citation: Menesi FA, Sherif FM, El-Gharadwi M, et al.A comparative study of metformin alone, in combination with insulin or metformin plus insulin in presence of simvastatin in libyan diabetic patients. Pharm Pharmacol Int J. 2017;5(2):58-62. DOI: I0.15406/ppij.20I7.05.00I I6 


\section{Discussion}

In this study, all the treated patients in the three groups had a significant FBG control. Thus, FBG was unchanged among all the treated groups and a very good glycaemic control in metformin and insulin treated group. PPBG among the three treated groups showed a good control with a profound reduction in metformin and insulin diabetic patients. The values of HbAlc of the treated patiennts within the target range but metformin and insulin treated group indicated a better HbAlc control. The present findings are in consistent with the fact of synergistic effect of the two anti-hyperglycaemic drugs combination. ${ }^{18}$ The combination of metformin and insulin may be an attractive therapeutic option for patients with DM whose hyperglycemia is poorly controlled on insulin. Aviles et al. ${ }^{19}$ stated that a combination therapy of insulin and metformin causes more improvement in glycaemic control and more reduce $\mathrm{HbAlc}$ in compare with increased frequency of dosage of insulin. Furthermore, unchanged FBG and PPBG and $\mathrm{HbA} 1 \mathrm{c}$ in patients on metformin and insulin compared to metformin, insulin and simvastatin patients. The $\mathrm{HbAlc}$ diabetic patients on simvastatin showed a slight elevation as compared to other groups. Previous studies showed that statin use is associated with a rise of FPG in patients with and without DM. ${ }^{20}$ Others $^{21}$ have identified deterioration in glucose homoeostasis in patients treated with statins and this depends on lipid solubility of statins. Simvastatin has a high lipid solubility and can enter extra hepatic cells easily and may suppress isoprenoid protein synthesis, thus attenuating the action of insulin. The abnormality of FBG may translate into clinical syndrome of DM with rise in $\mathrm{HbAlc}$ is not excluded.

This study was also aimed to compare effects of metformin alone and in combination on lipid profile of diabetics. No change in TC, TG, LDL-C and HDL-C in metformin and insulin. This effect may be due to a better glycaemic control attained by both drugs regimen which enables additional improvement in lipid profile ${ }^{22}$ with no change in $\mathrm{AI}$ of the patients. TC and LDL-C were also decreased in metformin, insulin and simvastatin group. It is well established that simvastatin acts by inhibiting of HMG-COA- reductase, the rate limiting step enzyme in cholesterol biosynthesis and so produces a decrease in TC, LDL-C and TG with a slight increase in HDL-C. ${ }^{23}$ HDL-C level showed a less increased in patients on simvastatin while TG was not affected. Due to pervious effects of simvastatin on lipid parameters, the AI was decreased in diabetics on simvastatin. Simvastatin causes profound decreased TC and LDL-C and less increased HDL-C. This finding is in line with studies of simvastatin that has more effect on TC and LDL-C than HDL-C but with little or no effect on TG. ${ }^{24}$

In this study, no changes in ALT, AST, ALP and bilirubin in diabetics on metformin alone or with others were obtained. Lobevitz and $\mathrm{Kreide}^{25}$ demonstrated no evidence of hepatotoxic effect or ALT abnormality in patients on metformin or insulin. This is in line with the present findings of a good glycaemic control. This supports the important link among glycaemic control, insulin resistance and hepatic function and suggests that improved glycaemic control and improvement of insulin resistance can reduce a mild chronic elevation of transamnitis often found in diabetic patients. ${ }^{26}$ Furthermore, no changes were seen in ALT, AST and ALP in patients on metformin and insulin compared to metformin, insulin and simvastatin. These findings are in agreement with previous studies of unchanged of LFT in simvastatin treated diabetics and unchanged of ALT and AST. It demonstrated of no abnormality in biochemical safety parameters and no consistent adverse clinical or biochemical effects are observed during the therapy with simvastatin. ${ }^{27,28}$ The American college of physicians suggest that diabetics with other CV risk factors should take statin for primary prevention of macrovascular complications. These patients do not need routine monitoring of LFT who are on statins unless they have baseline abnormalities of LFT or they are using drugs that could increase the risk of adverse events. ${ }^{29}$ Further, for diabetics with baseline transaminases less than three times the upper limit of normal, it is not contraindicated to initiate, continue on advance statins therapy as long as the patients are carefully monitored. Only high dose statins therapy is associated with more frequent abnormalities of LFTs, although they are still relatively infrequent. ${ }^{30}$ In contrast to bilirubin which showed a profound increased in patients on simvastatin, the authors reported that bilirubin increased after simvastatin treatment in dependent of changes in the liver enzymes. ${ }^{31}$ The interesting point which was observed during the assessment of lipid profile of diabetics subjected to treatment by three different doses of simvastatin $(10,20$ and $40 \mathrm{mg})$ is that the dose dependent effect of simvastatin and by comparing to the lipid modifying efficacy of simvastatin at the three different doses. The analysis indicate no change in TC, TG, and LDL-C in patients taken $10 \mathrm{mg}$ simvastatin as compared to $20 \mathrm{mg}$. Although a profound decreased TC and LDL-C were observed in patients treated with $40 \mathrm{mg}$ simvastatin as compared to 10 and $20 \mathrm{mg}$. The HDL-C showed slight but no improvement though out the three different doses. The AI showed a significant decreased at a dose of $40 \mathrm{mg}$ as compared to a lower doses of simvastatin. A similar finding was reported by Peter et al. ${ }^{32}$ that during comparing of lipid lowering efficacy of statins, simvastatin showed a lesser efficacy in TC and LDL-C reducing and lesser percentage in HDL-C increasing with simvastatin increased doses and across dose range. Also, the present finding is in agreement with the previous studies that increasing simvastatin dose to $20 \mathrm{mg} /$ day resulted only in marginal further reduction of serum TC. ${ }^{33}$ With regard to renal function (urea and creatinine), no change was detected in patients on metformin alone and on metformin, insulin and simvastatin which may indicate a safety of the drugs. In conclusion, the efficacy of metformin in controlling hyperglycemia was enhanced when combined with insulin without negative effects. Metformin showed a good safety profile on hepatic and renal functions of diabetics and simvastatin, as a lipid lowering drug, was effective in controlling of dyslipidemia associated with diabetes and produced a profound reduction in TC and LDL-C of diabetic patients.

\section{Acknowledgements}

None.

\section{Conflict of interest}

Author declares that there is no conflict of interest.

\section{References}

1. $\mathrm{Hu}$ FB. Globalization of Diabetes: The role of diet, lifestyle, and genes. Diabetes Care. 2011;34(6):1249-1257.

2. Shlomo M, Kenneth S, Polonk P. Williams textbook of endocrinology. 12th ed. USA: Elsevier/Saunders; 2011. p. 1371-1435

3. Oputa RN. Diabetes mellitus: a global epidemic with potential solutions. African Journal of Diabetes Medicine. 2012;20(2):33-35.

4. World Health Organization. Definition, diagnosis and classification of diabetes mellitus and its complications. 1999. 
5. Kirpichnikov D, McFarlane SI, Sowers JR. Metformin: an update. Ann Intern Med. 2002;137(1):25-33.

6. Hundal R, Krssak M, Dufour S, et al. Mechanism by which metformin reduces glucose production in type 2 diabetes. Diabetes. 2000;49(12):2063-2069.

7. Towler MC, Hardie DG. AMP-activated protein kinase in metabolic control and insulin signaling. Circ Res. 2007;100(3):328-341.

8. Zhou G, Myers R, Li Y, et al. Role of AMP-activated protein kinase in mechanism of metformin action. J Clin Invest. 2001;108(8):1167-1174.

9. Miller RA, Chu Q, Xie J, et al. Biguanides suppress hepatic glucagon signalling by decreasing production of cyclic AMP. Nature. 2013;494(7436):256-260

10. Collier CA, Bruce CR, Smith AC, et al. Metformin counters the insulin-induced suppression of fatty acid oxidation and stimulation of triacylglycerol storage in rodent skeletal muscle. Am J Physiol Endocrinol Metab. 2006;291(1):E182-E189.

11. Sherif FM, Ahmed SS. Diabetes and hypertension. Int Diabetes Digest. 1997;8:1-5

12. Cedeberg H, Stanckova A, Yaluri N, et al. Increased risk of diabetes with statin's treatment is associated with impaired insulin sensitivity and insulin secretion: a 6year follow-up study of the METSIM cohort. Diabetologia. 2015;58(5):1109-1117.

13. Chagtu B, Magazine R, Bairy KL. Statins and risk of diabetes mellitus. World J Diabetes. 2015;6(2):352-357.

14. Miettinen TA. Diurnal variation of cholesterol precursors squalene and methyl sterols in human plasma lipoproteins. $J$ Lipid Res. 1982;23(3):466-473.

15. Brault M, Roy J, Gomez Y, et al. Statin treatment and new- onset diabetes. A review of proposed mechanism. Metabolism. 2014;63(6):735-745.

16. Klaus PG. Interaction between glucose and lipid metabolism: More than diabetic dyslipidemia. Diabetes Metab J. 2015;39:353-362.

17. Rahman MH, Durrai VEL, Janardah B. Evaluation of the anti hyperlipidemic and anti atherosclerotic activities of ethanolic extract cissus pallid in atherogenic diet fed rats. Int $J$ Pharmaceut Res Scholars. 2013;6(2):1-3.

18. Wulffele MG, Kooy A, De Zeeuw D. The effect of metformin on blood pressure, plasma cholesterol and triglycerides in type 2 diabetes mellitus: a systematic review. $J$ Int Med. 2004;256:1-14.

19. Aviles-Santa L, Sinding J, Raskin P. Effects of metformin in patients with poorly controlled insulin-treated type 2 diabetes mellitus. Ann Intern Med. 1999;131(3):182-188.
20. Sukhija R, Prayaga S, Marashdeh M, et al. Effect of statins on fasting plasma glucose in diabetic and nondiabetic patients. J Investig Med. 2009;57(3):495-499.

21. Sattar N, Preiss D, Murray HM, et al. Statins and risk of incident diabetes: a collaborative meta-analysis of randomized statin trials. Lancet. 2010;375(9716):735-742.

22. Sona V, Regi J. Effects of insulin, glimepiride and combination therapy of insulin and metformin on blood sugar and lipid profile of NIDDM patients. Indian J Clin Biochem. 2009;24(2):175-178.

23. Darioli R, Bovet P, Brunner HR, et al. Evaluation of tolerance, efficacy and safety of 3-year simvastatin use in the treatment of primary hypercholesterolemia. Schweiz Med Ochenschr. 1990;120(4):85-91.

24. Findlay M. Simvastatin clinical profile. Amer J Med. 1989;87:544-546.

25. Lebovitz H, Kreider M, Freed M. Evaluation of liver function in type 2 diabetic patients during clinical trials: evidence that rosiglitazone does not cause hepatic dysfunction. Diabetes Care. 2002;25(5):815-821.

26. Elizbeth H, Hrris MD. Elevated liver function test in type 2 diabetes. Clinical Diabetes. 2005;23(3):115-118.

27. Shepherd J, Blauw GJ, Murphy MB, et al. Pravastatin in elderly individuals at risk of vascular disease (PROSPER): a randomized controlled trial. Lancet. 2002;360(9346):1623-1630.

28. Scott RS, Lintott CJ, Wilson MJ. Simvastatin and side effects. $N Z$ Med J. 1991;104:493-495.

29. Snow V, Aronson M, Hornbake R, et al. Lipid control in the management of type 2 diabetes mellitus: a clinical practice guideline from the American College of Physicians. Ann Intern Med. 2002;140(8):644-650.

30. Larosa JC, Grundy SM, Waters DD, et al. The Treating to New Targets (TNT) Investigators: Intensive lipid lowering with atorvastatin in patients with stable coronary disease. $N$ Engl J Med. 2005;352:1425-1435.

31. De Nolting PRW, Kusters DM, Hutten, et al. Serum bilirubin levels in familial hypercholestrmia: a new risk marker for cardiovascular disease?. J Lipid Res. 2011;52(9):1755-1759.

32. Peter H, Michael H, Evan A. Comparison of the efficacy and safety of rosuvaststin versus atorvaststin, simvatatin, and paravastatin across doses. Amer J Card. 2003;93:152-160.

33. Arnadottir M, Eriksson L, Germerhasen J. Low-dose simvastatin is a well tolerated and efficacious cholesterol-lowering agent in ciclosporin-treated kidney transplant recipients. Nephron. 1994;68(1):57-62. 